\title{
Práticas letradas digitais no contexto do Teletandem: um estudo de caso
}

\author{
Rickison Cristiano de Araújo Silva \\ Universidade Federal de Campina Grande \\ rickison_cristiano@hotmail.com \\ Fábio Marques de Souza \\ Universidade Estadual da Paraíba \\ fabiohispanista@gmail.com
}

\section{Resumo}

Este trabalho identifica e analisa as práticas letradas digitais presentes nas interações de Teletandem, de um par interagente. Essas interações foram realizadas durante o desenvolvimento do componente curricular "Práticas de intercâmbio linguístico-cultural via Teletandem", desenvolvido no curso de Letras - Espanhol, da Universidade Estadual da Paraíba - UEPB. Trata-se de um estudo de caso etnográfico de cunho qualitativo (ANDRÉ, 1995; LUDKE; ANDRÉ, 1986; VÓVIO; SOUZA, 2005), cuja análise está centrada em uma interação de Teletandem realizada e gravada pelo Skype por uma brasileira e uma argentina. As discussões estão fundamentadas nos Novos Estudos do Letramento (STREET, 1993), especificamente no conceito de práticas de letramento (STREET, 2012) e Letramentos Digitais (BUZATO, 2006). Os dados analisados indicam que o Teletandem pode ser caracterizado como um contexto virtual de aprendizagem que suscita práticas letradas digitais por parte das interagentes, exigindo habilidades e conhecimentos técnicos para a efetivação dessas práticas, bem como a presença de práticas letradas digitais híbridas.

Palavras-chave: Práticas letradas digitais. TDICs. Teletandem.

\begin{abstract}
This paper aims to identify and analyze the digital literacy practices of an interacting pair present in Teletandem interactions carried out through the curricular component "Practices of linguistic-cultural exchange via Teletandem", developed in the Language Arts Course (Spanish), of State University of Paraíba UEPB. This is a qualitative ethnographic case study (ANDRÉ, 1995; LUDKE; ANDRÉ, 1986; VÓVIO; SOUZA, 2005), which analysis is centered on a
\end{abstract}


Teletandem interaction performed and recorded by Skype by a Brazilian and an Argentinian. The discussions are based on the New Literacy Studies (STREET, 1993), specifically on the concept of literacy practices (STREET, 2012) and Digital Literacies (BUZATO, 2016). The analyzed data point to Teletandem as a virtual learning context which raises digital literacy practices on the part of the interactants, requiring skills and technical knowledge to perform these practices, as well as the presence of hybrid digital literacy practices.

Keywords: Digital literate practices. TDICs. Teletandem.

\section{Considerações iniciais}

$\mathrm{Na}$ contemporaneidade, as Tecnologias Digitais da Informação e Comunicação - doravante TDICs - têm proporcionado transformações nas mais diversas esferas, sejam elas sociais, culturais ou educacionais, influenciando diretamente as formas de interação, comunicação, leitura e escrita. Essas transformações acabam afetando a formação de professores e $\mathrm{a}(\mathrm{s})$ forma(s) como se ensina e se aprende uma língua, materna ou estrangeira.

A partir disso, os cursos de formação de professores de línguas são convidados a questionar e a refletir sobre as TDICs como eixos importantes da formação e da prática docente dos profissionais de ensino de línguas. De acordo com Freire e Leffa (2013), verifica-se que alguns cursos de formação de professores de línguas têm apresentado uma realidade distante no que se refere à presença das TDICs, tanto no viés reflexivo quanto no prático. Isso quer dizer que não há fomento aos letramentos digitais. Esses letramentos não se limitam à apropriação da máquina, mas incluem o desenvolvimento de habilidades para produção de práticas nos espaços tecnológicos. Essa perspectiva é necessária visto que os perfis de alunos que encontramos em sala de aula incluem os ditos nativos digitais ${ }^{1}$ (PRENSKY, 2001; BUZATO, 2006; COSCARELLI, 2016; PINHEIRO, 2018).

Neste cenário, o curso de Letras - Espanhol da Universidade Estadual da Paraíba, através do Componente Curricular (CC) "Práticas de intercambio linguístico-cultural via Teletandem" tem buscado proporcionar

1 Entende-se por nativos digitais aquelas pessoas que nasceram e cresceram interagindo com as Tecnologias Digitais (PRENSKY, 2001). 
aos seus alunos uma formação docente e um processo de ensino e aprendizagem de língua espanhola, associados aos letramentos digitais através das interações de Teletandem. Teletandem caracteriza-se como um excelente contexto que possibilita o contato do aluno com pessoas de diferentes países e culturas. Esse contato se dá por meio do computador e da internet, comunicação em tempo real, utilizando programas ou aplicativos tais como o Skype e Hangouts, entre outros. Assim, o aluno participa de práticas letradas digitais que transformam a sua forma de pensar, aprender e se comunicar.

Dada essa perspectiva para formação de novos professores, nos perguntamos: Que práticas letradas digitais estão presentes nas interações de Teletandem realizadas através do componente curricular "Práticas de intercâmbio linguístico-cultural via Teletandem”?. Para respondermos a esse questionamento, identificamos e analisamos as práticas de letramentos digitais presentes nas interações de Teletandem de um par interagente ${ }^{2}$, durante o desenvolvimento do componente curricular "Práticas de intercâmbio linguístico-cultural via Teletandem", do curso de Licenciatura em Letras - Espanhol, da Universidade Estadual da Paraíba.

Este artigo está organizado em quatro momentos, precedidos destas considerações iniciais e excetuando as referências. No primeiro, subdividido em dois momentos descrevemos o percurso metodológico realizado ao longo da pesquisa. No segundo, também subdividido em dois momentos, apontamos as discussões teóricas sobre os Novos Estudos do Letramento e Letramentos Digitais, respectivamente. No terceiro momento, são apresentadas as análises e discussões sobre as práticas letradas digitais nas interações de Teletandem. Por fim, no quarto momento, expomos as considerações finais.

\section{Percurso metodológico}

\subsection{Tipo de pesquisa}

Este trabalho é um estudo de caso etnográfico (ANDRÉ, 1995), de caráter qualitativo (LUDKE; ANDRÉ, 1986; VÓVIO; SOUZA, 2005).

2 Termo utilizado para se referir aos participantes de uma interação (português/espanhol).

Horizontes de Linguística Aplicada, ano 18, n. 2, 2019 
Esse tipo de estudo caracteriza-se como qualitativo por possibilitar aos investigadores o contato de forma direta com os participantes e estudar os acontecimentos no local onde eles se materializam sem que haja uma manipulação de dados. Isso permite o "exame mais aprofundado das interações entre os sujeitos e do modo como essas interações ocorrem em determinados contextos. Focaliza o problema de como as pessoas interagem e negociam com a cultura e apropriam-se dela" (VÓVIO; SOUZA, 2005, p.49), perspectivas presentes nas interações de Teletandem.

Para Ludke e André (1986), nas pesquisas qualitativas, os dados gerados e coletados necessitam ser bastante descritivos e os pesquisadores devem estar atentos para o maior número de elementos presentes na situação estudada. Em nosso caso, buscamos verificar que práticas de letramentos digitais estão presentes nas interações.

É um estudo de caso etnográfico (ANDRÉ, 1995), pois estamos interessados em compreender casos particulares, levando em consideração o contexto específico, que são as interações de Teletandem, e as suas complexidades. André (1995) pontua que o que se tem realizado em pesquisas como essas é uma adaptação da etnografia à educação, levandonos a desenvolver estudos, como o nosso, de base etnográfica e não em sua completude, no sentido strictu da pesquisa etnográfica antropológica.

\subsection{Contexto, participantes e instrumentos de coleta e geração de dados}

Esta pesquisa foi desenvolvida ${ }^{3}$ no curso de Licenciatura em Letras - Espanhol da Universidade Estadual da Paraíba, Campus I - Campina Grande, no componente curricular "Práticas de intercâmbio linguísticocultura via Teletandem", de caráter eletivo e com carga horária de 60 horas.

O Teletandem, uma das formas de fazer tandem ${ }^{4}$, é um contexto colaborativo, autônomo e recíproco de aprendizagem a distância de línguas

${ }^{3}$ Aprovada pelo comitê de Ética e Pesquisa em 19 de fevereiro de 2019. CAAE: 06702818.3.0000.5182/ $\mathrm{N}^{\mathrm{o}}$ do parecer: 3.155.461. Os dados aqui analisados fazem parte da pesquisa "A formação do professor interculturalista de língua espanhola mediada pelo teletandem: crenças, ações e reflexões", que vem sendo realizada pelo primeiro autor, sob a orientação do segundo autor.

4 A aprendizagem em Tandem, apesar de pouco usual no Brasil, surgiu inicialmente na Alemanha ao final dos anos 60, seu objetivo está na aprendizagem de línguas estrangeiras através de sessões bilíngues. A prática em Tandem pode ser Horizontes de Linguística Aplicada, ano 18, n. 2, 2019 
estrangeiras entre pares falantes (nativos ou competentes) que possuem o objetivo de aprender o idioma do outro. Para isso, utilizam-se programas/aplicativos que possibilitam uma comunicação síncrona, viabilizando a produção e a compreensão oral e escrita dos interagentes a partir do uso de microfone e webcam, realizando um intercâmbio de conhecimentos linguísticos e interculturais (VASSALLO; TELLES, 2009).

Temos como participantes da pesquisa um par $^{5}$ de interagentes (português/espanhol), uma brasileira e uma argentina. O par é composto por Paula 6 , brasileira de 22 anos, cursando o último período de Letras Espanhol, matriculada no componente curricular, necessitando realizar as interações de Teletandem, solicitadas ao longo do componente. Luna, participante argentina de 22 anos, cursa Tecnicatura Superior em Inglês para el Turismo ${ }^{7}$, matriculada na disciplina Língua e Cultura Portuguesa 1, participando espontaneamente das interações. A escolha do par interagente se deu por terem sido as primeiras alunas a formarem os pares (português/espanhol) e por realizarem as seis interações propostas pelos seus professores.

Para a realização do estudo, utilizamos a primeira interação, dado o grau de complexidade e informações que ela por si só apresenta, para identificar e analisar as práticas letradas digitais presentes durante as interações orais/escritas no Teletandem. As transcrições foram realizadas,

realizada de três formas: i) Face a face, denominada forma presencial, na qual a comunicação é predominantemente oral, porém, a qualquer momento poderá ser utilizado algum material escrito; ii) E-tandem, refere-se à conversação síncrona e assíncrona, de forma eletrônica, através principalmente de e-mail ou chats, sendo a escrita a forma de comunicação mais abordada; e iii) Teletandem, interação completa, na qual há presença da escrita e do audiovisual, a interação entre os participantes acontece em tempo real graças a programas de comunicação gratuitos através da internet (VASSALLO; TELLES, 2009; BENEDETTI, 2010; SILVA; SOUZA, 2019).

5 A participação da aluna argentina se deu através da parceria e mediação da professora Liliana Roxana Rubín, do Profesorado Superior de Lenguas Vivas, localizada na Provincia de Salta, Argentina, responsável pelo componente curricular Lengua y Cultura Portuguesa I.

${ }^{6}$ Visando a proteção dos participantes, todos os nomes aqui apresentados são fictícios.

${ }^{7}$ Técnico Superior em inglês para Turismo.

Horizontes de Linguística Aplicada, ano 18, n. 2, 2019 
sem alterações linguísticas e na língua utilizada, adotando alguns símbolos apresentados por Preti (1999).

\section{Fundamentação teórica}

\subsection{Do letramento aos novos estudos do letramento}

A palavra literacy, pode ser compreendida no inglês tanto como "alfabetização" quanto "letramento", após ser traduzida para diferentes países e utilizada por diversos pesquisadores em contextos distintos, ganhou uma variedade de termos e conceitos que se divergem. Não muito diferente, no Brasil, a partir da década de 80, começou-se a utilizar letramento como tradução do termo literacy em língua inglesa, que, para alguns estudiosos, apresenta uma relação (in)direta com alfabetização (FIAD, 2015; OLIVEIRA, 2017).

De acordo com Soares (2004), se fazia necessária a utilização do termo letramento, uma vez que seu uso tinha como intenção diferenciar e evitar confusão acerca das práticas de leitura e escrita no domínio do código da língua escrita, ou seja, a alfabetização. Assim, letramento para Soares (2009, p.47) é compreendido como "estado ou condição de quem não apenas sabe ler e escrever, mas cultiva e exerce as práticas sociais que usam a escrita".

Já para Kleiman (1995, p.19), o letramento atua "como um conjunto de práticas sociais que usam a escrita, enquanto sistema simbólico e enquanto tecnologia, em contextos específicos, para objetivos específicos". Dito isso, estabelecemos o conceito de letramentos como plural, mas que, para além do que distingue cada acepção, compreende o uso da escrita como uma prática social, plural e heterogênea. Essa perspectiva advém dos Novos Estudos do Letramento (NEL) (STREET, 2010).

Os Novos Estudos do Letramento (NEL), traduzido da proposta New Literacy Studies - NLS de Street (1993), surgem em oposição à perspectiva dos estudos sobre literacy. Essa nova propositura apresenta um novo olhar e uma nova perspectiva para o uso da escrita e leitura sem dar tanta ênfase à aquisição de habilidades, mas sim às práticas sociais que as permeiam (STREET, 2010, 2012), com a presença de crenças, valores e de 
várias visões de mundo. Assim, as interações entre os sujeitos e a escrita se revelam bastante complexas.

Nesse sentido, os NEL adotam a perspectiva de letramentos mais ampla, uma vez que vão além do contexto escolar, e consideram os múltiplos contextos. O tipo de letramento é, então, ressignificado, ou seja, o tipo de letramento compreendido como neutro, homogêneo e autônomo dá espaço aos letramentos que apresentam diferentes usos e significados para a escrita e leitura nos mais variados contextos de práticas sociais situadas, reconhecendo a multiplicidade existente de letramentos. Assim, Street (2006, p. 466) pontua:

Prefiro trabalhar com base no que chamo de modelo "ideológico" de letramento, o qual reconhece uma multiplicidade de letramentos; que o significado e os usos das práticas de letramento estão relacionados com contextos culturais específicos; e que essas práticas estão sempre associadas com relações de poder e ideologia: não são simplesmente tecnologias neutras.

Percebe-se, dessa forma, a adoção, por parte de Street, do modelo ideológico ao invés do autônomo (STREET, 2006, 2010), modelos construídos pelo próprio estudioso. O modelo autônomo considera a escrita como um ato individual, neutro, descontextualizado e não leva em consideração as condições sociais, diferentemente do modelo ideológico.

A partir do viés apresentado pelo modelo de letramento ideológico como práticas sociais, e das oportunidades pontuada por Silva (2019, p. 203) de "identificar questões ideológicas e políticas que permeiam os múltiplos letramentos situados nos diferentes contextos", Street (2012) propõe os conceitos de eventos e práticas de letramento.

Os eventos de letramento, conceito proposto por Heath (1982 apud STREET, 2012) seriam qualquer situação na qual há presença de algum texto escrito fazendo parte integrante da natureza entre os participantes, bem como de seus processos interativos. Em contrapartida, Street (1984 apud STREET, 2012, p.74) cria o conceito de práticas de letramento, ao defender que os eventos de letramento por si só não abarcam a amplitude da cultura escrita, para se referir "as práticas e as concepções sociais da leitura e da escrita”, no qual há uma ampliação das práticas sociais e da 
concepção cultural que permeia os atos de pensar e fazer a escrita e a leitura.

Neste sentido, compreende-se que as práticas de letramento

variam com o contexto cultural, não há um letramento autônomo, monolítico, único, cujas consequências para os indivíduos e sociedades possam ser inferidas como resultados de suas características intrínsecas. Como argumentei anteriormente, em lugar disso há 'letramentos', ou melhores 'práticas de letramento', cujo caráter e consequências têm de ser especificados em cada contexto. (STREET, 2012, p.82).

Pontuamos que nosso estudo está voltado para as práticas de letramentos digitais nas interações de Teletandem. Consequentemente, nos ancoramos no conceito de práticas de letramento, principalmente por apresentarem um caráter múltiplo e diverso, conectado a crenças, modos de vida e valores, dependendo de como as pessoas fazem uso da escrita e da leitura no seu dia a dia.

\subsection{Letramento digital}

Sabe-se que as TDICs estão presentes no nosso dia a dia, fazendo com que o seu uso seja cada vez mais integrado aos diversos contextos sociais e educacionais por parte dos professores e alunos, bem como das instituições responsáveis pela formação docente. Desta forma, com a integração das TDICs às práticas sociais, percebem-se as transformações que elas ocasionam nas formas de interação e comunicação entre as pessoas, bem como as diferentes funcionalidades e significados que lhes são atribuídos.

Dudeney, Hockly e Pegrum (2016) pontuam que o ensino de línguas na contemporaneidade não deve ser caracterizado somente no letramento impresso, compreendido como uma habilidade de entender e gerar uma variedade de textos escritos que estão relacionados a gramática, vocabulário e outros pontos que estão relacionados à leitura e à escrita, pois é "fraudar nossos estudantes no seu presente e em suas necessidades futuras" (DUDENEY; HOCKLY; PEGRUM, 2016, p.19).

Neste sentido, Pinheiro (2018) sinaliza o surgimento e a formação de um conceito que expressa tanto a imersão das tecnologias em diferentes 
contextos da nossa sociedade, quanto para as novas práticas advindas delas, o chamado letramento digital. Segundo a estudiosa, esse termo possui várias definições, uma vez que as tecnologias nos apresentam diferentes perspectivas e diversificadas práticas sociais, e uma rapidez no surgimento de novas ferramentas e possibilidades que com elas advém.

Buzato (2006, p.16) utiliza-se do termo letramentos, no plural, perspectiva adotada neste trabalho, para inferir que são práticas sociais e culturais que possuem sentidos e objetivos específicos dentro de um grupo social. Assim, conceitua os Letramentos Digitais (LDs) como:

Conjuntos de letramentos (práticas sociais) que se apoiam, entrelaçam e apropriam mútua e continuamente por meio de dispositivos digitais para finalidades específicas, tanto em contextos socioculturais geograficamente e temporalmente limitados, quanto naqueles construídos pela interação mediada eletronicamente (BUZATO, 2006, p. 16).

Essa perspectiva sobre os letramentos digitais, segundo Buzato (2006), resulta em dois corolários: (i) a noção de letrado digital como uma condição, uma vez que os LDs são híbridos e instáveis e (ii) a influência do contexto e as culturas nas quais estão inseridos.

Lins e Souza (2016), voltando-se de forma específica para a área de ensino e aprendizagem de línguas mediada pelas TDICs, propõem que os letramentos digitais podem ser compreendidos como a habilidade de realizar e entender os textos no contexto digital, além de poder interagir no mundo virtual. Essas perspectivas são postas como um aspecto relevante, uma vez que "a apropriação desse letramento converge para o bom desempenho do participante durante o complexo processo de aquisição, troca, interação e compartilhamento de aprendizagens no universo virtual" (LINS; SOUZA, 2016, p.58).

Dessa forma, sinalizamos que o nosso olhar referente aos letramentos digitais está na direção do pluralismo que o conceito apresenta, seja no conhecimento e na apropriação das ferramentas tecnológicas como o teclado, mouse, ligar o computador, acessar a internet entre outros, seja no desenvolvimento de habilidades para criar sentidos nas diversas práticas sociais desenvolvidas a partir das tecnologias. 


\section{Análise dos dados}

Parece-nos relevante e indispensável iniciarmos nossas análises pelo próprio Teletandem, um contexto digital de aprendizagem de línguas, que possibilita a comunicação, a troca de informações e de conhecimentos linguísticos e interculturais. Além disso, exige dos estudantes e dos futuros professores, o desenvolvimento de metodologias de ensino e aprendizagem para desenvolver as fases e suas especificidades. Os interagentes necessitam também apresentar letramentos digitais para a realização das interações no que se refere ao uso das tecnologias digitais, bem como das novas práticas sociais que esse contexto específico de interação apresenta.

Neste sentido, do ponto de vista teórico, consideramos que, ao realizarem interações de Teletandem, os participantes já estão inseridos em um contexto que, por si só, demanda práticas letradas digitais, uma vez que solicita a eles o conhecimento para manusear os recursos que os aplicativos e os programas disponibilizam para a realização da chamada de vídeo.

Paula e Luna foram os pares que completaram o maior número de interações ao longo do componente curricular, realizando seis interações ao total, enquanto outros pares realizaram somente três ou quatro interações ou nenhuma interação por vários motivos. Dentre esses motivos, estava o não conhecimento das tecnologias e a não habilidade para com as ferramentas advindas delas. Sobre isso, Telles e Maroti (2008) afirmam que muitas vezes os pares de Teletandem não conseguem lidar com as práticas de letramentos digitais antes e durante as interações, fazendo com que o computador e os programas se tornem obstáculos para a efetivação das interações e, consequentemente, do aprendizado, levando-os a desistir.

Para iniciarem as interações por vídeo chamada no Skype, as participantes deveriam conversar e realizar os ajustes tecnológicos necessários para a primeira interação, cujo tema seria família. Esses ajustes são considerados como práticas letradas digitais para a efetivação da interação. Podemos visualizar a seguir um trecho dessa interação por chat através da escrita, antes de iniciarem no audiovisual.

\section{[Excerto 01]}

10/05/2019 14:06 Luna: Ya me conecté jaja con mi celular 10/05/2019 14:06 Paula: ¡qué bueno!

10/05/2019 14:06 Paula: Estaba organizando para la grabación 10/05/2019 14:08 Luna: Bueno, ¿ya está todo listo? 
10/05/2019 14:08 Paula: Sí

10/05/2019 14:08 Paula: ¿llamo o tú llamas?

10/05/2019 14:08 Paula: jajajaja

10/05/2019 14:09 Luna: ¿Seria con vídeo llamada?

10/05/2019 14:09 Luna: Primera vez que uso esto jajaja

10/05/2019 14:09 Paula: Sí jajaja

10/05/2019 14:09 Paula: No te preocupes, te llamo y tu aceptas

10/05/2019 14:09 Paula: Quando terminamos eu encerro a chamada

10/05/2019 14:09 Paula: Se demorar a conectar é so esperar

10/05/2019 14:10 Luna: Bueno esta bien. (Interação $1^{8}$, por chat - Paula e Luna - 10 maio de 2019).

Ao longo desse primeiro contato das participantes, no excerto 01, percebemos que Luna está usando o celular para realizar as interações e que é a sua primeira vez no Skype, aplicativo não tão novo (lançado em 2003) e que imaginamos que ou ela teria conhecimento ou teria testado antes com outra pessoa para realizar as interações, uma vez considerada nativa digital. Porém, como percebemos no excerto 1 , esse fato não foi um impedimento para que a interação acontecesse, já que Paula, também nativa digital, possui conhecimento técnico/usual sobre o aplicativo e se disponibilizou para iniciar e finalizar a chamada de vídeo, bem como instruir a participante Luna.

${ }^{8}$ Tradução nossa:

10/05/2019 14:06 Luna: Já me conectei kkkkk com meu celular 10/05/2019 14:06 Paula: que bom!

10/05/2019 14:06 Paula: Estava organizando para a gravação

10/05/2019 14:08Luna: Bom, já está tudo pronto?

10/05/2019 14:08 Paula: Sim

10/05/2019 14:08 Paula: chamo ou você chama? 10/05/2019 14:08 Paula: kkkkk

10/05/2019 14:09 Luna: Seria com vídeo chamada?

10/05/2019 14:09 Luna: Primeira vez que uso isto kkk

10/05/2019 14:09 Paula: Sim kkk

10/05/2019 14:09 Paula: Não te preocupes, te chamo e tu aceita

10/05/2019 14:09 Paula: Quando terminamos eu encerro a chamada

10/05/2019 14:09 Paula: Se demorar a conectar é so esperar

10/05/2019 14:10 Luna: Bom esta bem

( $1^{\circ}$ Interação, por chat - Paula e Luna - 10 maio de 2019).

Horizontes de Linguística Aplicada, ano 18, n. 2, 2019 
Não obstante esse desconhecimento técnico apresentado por Luna, notamos que há presença de práticas letradas digitais através da escrita, uma vez que ela consegue interagir com Paula pelo Skype. Coscarelli (2016) lembra que os letramentos digitais estão justamente nesse paralelo da capacidade de realizar ações digitais bem-sucedidas de acordo com a situação em que o indivíduo está situado. Na interação sob análise essa prática letrada digital foi provocada por meio do uso das ferramentas apresentadas pelo aplicativo, a de enviar mensagens através do teclado do celular.

Ao iniciarem a interação em vídeo chamada, as duas participantes conferem se estão se ouvindo e decidem que Paula iniciará a falar sobre o tema. Em seguida, a brasileira pede um momento para organizar a tela do seu Skype, para que seja ampliada sua imagem. Vejamos:

\section{[Excerto 02]}

Paula: ¿Quieres empezar o yo empiezo?

Luna: eh::: como vos querrás

Paula: Entonces, yo voy a empezar un poco

Paula: Solo organizar un poquito aquí

Luna: bueno

Paula: (...) ampliar um poco mi foto ...

Luna: unrum

Paula: (deixa eu colocar aqui). (Interação $1^{9}$, em Teletandem Paula e Luna - 10 maio de 2019, ênfase nossa).

A respeito do excerto 2 e demais interações, notamos que Paula sempre esteve preocupada com a organização e execução das sessões,

${ }^{9}$ Tradução nossa:

Paula: você quer começar ou eu começo?

Luna: eh::: como você quiser

Paula: Então eu vou começar um pouco

Paula: So organizar um pouquinho aqui

Luna: bom

Paula: (...) ampliar um pouco a minha foto ...

Luna: unrum

Paula: (deixa eu colocar aqui). (Interação 1, em Teletandem - Paula e Luna - 10 maio de 2019, ênfase nossa). 
principalmente no que tange à parte funcional, sempre disponibilizando seus conhecimentos e habilidades sobre as TDICs.

Como o tema da interação era família, as participantes decidiram utilizar fotografias pessoais para mostrar imagens de seus parentes, de como eram na infância e de como estão atualmente. Paula iniciou mostrando suas fotos de forma impressa e, logo em seguida, Luna, a participante argentina, também apresenta as fotos. Paula afirma ainda que enviará outras fotos suas, quando a interação acabar, e assim o faz. Dessa forma, as participantes, ao utilizarem as fotografias impressas em uma interação digital, fazem com que observemos um movimento de práticas letradas digitais híbridas que se apoiam em práticas letradas impressas (COSCARELLI, 2016), ou seja, a interação além do contexto digital. O que essa interação com uso de fotos impressas nos mostra é a (grande) influência do impresso na era digital. Apesar de estarmos inseridos em um contexto que solicita práticas letradas digitais e que utilizemos ferramentas tecnológicas no dia a dia, nossos hábitos ainda permanecem, em alguns casos, solidificadas no paradigma impresso.

Em outro momento da interação, Paula e Luna começam a tratar de aspectos culturais de suas cidades no que se refere aos festejos que nelas acontecem. Durante o diálogo, Paula decide enviar uma foto de sua cidade, de sua própria autoria, através do Skype, durante a interação audiovisual.

Sobre esse ponto, gostaríamos de sinalizar duas perspectivas relevantes: (i) o caráter intercultural presente durante a interação, viés importantíssimo na concepção de letramentos abordada neste trabalho, indicando práticas sociais que possibilitam a compreensão do outro e o respeito para com a diversidade que ultrapassa o viés linguístico. Essa perspectiva se concretiza ao explorarem curiosidades referentes a aspectos culturais que diferem do seu de origem, possibilitando, assim, a aprendizagem intercultural da língua do Outro por meio do Teletandem (TELLES, 2009) e (ii) o uso de práticas letradas digitais. Essa perspectiva intercultural acontece durante uma interação com o uso das tecnologias digitais, ou seja, o envio de fotos e discussões durante a interação. Esses recursos complementam as práticas letradas digitais ali desenvolvidos, práticas essas múltiplas que se (re)constroem na sua própria ação.

Percebemos também que há uma incorporação de letramentos audiovisuais durante as práticas letradas digitais nas interações de Teletandem. Esses letramentos audiovisuais, de acordo com Lins e Souza (2016, p. 56), estão conectados, sendo ferramentas indispensáveis e Horizontes de Linguística Aplicada, ano 18, n. 2, 2019 
importantíssimas, pois "permitem a interação linguística dos interagentes de línguas adicionais de maneira mais dinâmica e atrativa, além de permitir mostrar e compartilhar com o parceiro elementos culturais de seu país".

Em relação às práticas letradas digitais híbridas visualizamos a ocorrência em outro momento da interação, quando Luna, ao falar em português se apoia em um texto traduzido por ela online no Google Tradutor, transcrito à mão para o papel, fazendo com que ela o leia durante a interação. O que percebemos aqui são movimentos que se utilizam de ferramenta digital, Google Tradutor, mas que, ao final, essa prática letrada digital está calcada na escrita no papel.

Assim, o que constatamos, durante as interações de Teletandem são, segundo Buzato (2009), os mais diferentes letramentos praticados por um mesmo participante (interagente) que transita entre contextos culturais e de práticas diferentes, que necessita ampliar seus olhos sobre a tela, compreendendo as mais diversas linguagens que ali estão presentes (LINS; SOUZA, 2016).

\section{Considerações finais}

Este trabalho, orientado pela seguinte pergunta de pesquisa: Que práticas letradas digitais estão presentes nas interações de Teletandem realizadas através do componente curricular "Práticas de intercâmbio linguístico-cultural via Teletandem"?, nos possibilitou, ao analisar as interações realizadas por Paula e Luna, verificar que o próprio Teletandem é um contexto de aprendizagem que promove práticas letradas digitais. Nesse contexto, a comunicação só acontece através do apoio e da apropriação mútua das ferramentas tecnológicas, indo ao encontro à perspectiva de Letramentos Digitais apresentada por Buzato (2006) e aqui defendida.

Percebemos também que há uma mescla de práticas, ou seja, visualizamos a presença de práticas letradas digitais híbridas, uma vez que, em determinados momentos, as interagentes, inseridas em um contexto virtual, fazem usos dos recursos próprios do digital como os hiperlinks, envio de imagens digitais, sons, vídeos, compartilhamento de tela, entre outras ferramentas. Porém, vez ou outra, recorrem a materiais físicos e a textos escritos, atribuindo-lhes, dessa forma, um caráter híbrido, gerando, assim, práticas que não estão pautadas somente no digital. 
Constatamos também que o Teletandem fez com que Paula e Luna recorressem a outros tipos de Letramentos, como o audiovisual (LINS; SOUZA, 2016) em favor da realização das interações, que ademais de apresentar um fator linguístico, promove uma dimensão cultural, e o desenvolvimento da interculturalidade.

Ratificamos que nosso interesse não estava em compreender de forma comparativa as práticas letradas digitais de Paula e Luna, mas identificar e analisar que práticas foram realizadas por elas durante as interações de Teletandem. Assim, verificamos que quanto mais o aluno possuir conhecimento referente às TDICs e dominar suas habilidades, mais práticas letradas digitais serão realizadas nas interações de Teletandem, bem como em outros contextos que suscitam tais práticas. Dessa forma, defendemos que se fazem necessários uma formação docente e um processo de ensino e aprendizagem de línguas perpassados pela inserção e apropriação/reflexão crítica das possibilidades que as TDICs e os letramentos digitais apresentam.

\section{Referências}

ANDRÉ, Marli E. D. A. Etnografia da prática escolar. 4. ed. Campinas: Papirus, 1995.

BENEDETTI, Ana Maria. Dos princípios de tandem ao teletandem. In: BENEDETTI, A.M.; CONSOLO, D.A.; VIEIRA-ABRAHÃO, M.H. (Orgs.). Pesquisas em ensino e aprendizagem no Teletandem Brasil: línguas estrangeiras para todos. Campinas: Pontes, 2010. p.21-45.

BUZATO, Marcelo. Letramentos digitais e formação de professores. In: CONGRESSO IBERO-AMERICANO EDUCAREDE: EDUCAÇÃO, INTERNET E OPORTUNIDADES, 3, 2006, São Paulo. Anais... São Paulo: CENPEC, 2006, p. 1-13.

. Letramento e inclusão: do estado-nação à era das TIC. DELTA, São Paulo, v. 25, n. 1, p.1-38, 2009. Disponível em: http://www.scielo.br/scielo.php?pid=S010244502009000100001\&script=sc i_abstract\&tlng=pt. Acesso em: 12 maio. 2019.

COSCARELLI, Carla V. (Org.). Tecnologias para aprender. São Paulo: Parábola Editorial, 2016. 
Práticas letradas digitais no contexto do teletandem...

DUDENEY, Gavin; HOCKLY, Nicky; PEGRUM, Mark. Letramentos digitais. Trad. de Marcos Marcionilo. São Paulo: Parábola, 2016.

FIAD, Raquel S. Algumas considerações sobre os letramentos acadêmicos no contexto brasileiro. Pensares em Revista, São Gonçalo-RJ, n. 6, p. 23$34,2015$.

FREIRE, M. M.; LEFFA, Vilson J. A auto-heteroecoformação tecnológica. In: MOITA LOPES, L. P. da. (Org.). Linguística Aplicada na modernidade recente: Festschrift para Antonieta Celani. São Paulo: Parábola Editorial, 2013. p.59-78.

KLEIMAN, Angela B. (Org.). Significados do letramento: uma nova perspectiva sobre a prática social da escrita. Campinas: Mercado de Letras, 1995.

LINS, Elida F.; SOUZA; Fábio M. Letramento digital e audiovisual como potencializadores da aprendizagem colaborativa do português e do espanhol como línguas adicionais. EntreLínguas, Araraquara, v. 2, n. 1, p. 51-66, 2016.

LUDKE, Menga; ANDRÉ, Marli E.D.A. Pesquisa em educação: abordagens qualitativas. São Paulo: EPU, 1986.

OLIVEIRA, Giovane F. Os estudos dos letramentos acadêmicos no Brasil: influências, origens e perspectivas. DISSOL, Pouso Alegre, ano IV, n. 5, p. 89-101, 2017.

PINHEIRO, Regina C. Conceitos e modelos de letramento digital: o que escolas de ensino fundamental adotam? Linguagem em (Dis)curso, Tubarão, SC, v. 18, n. 3, p. 603-622, 2018.

PRETI. Dino. (Org). O discurso oral culto. 2. ed. São Paulo: Humanitas Publicações, FFLCH/USP, 1999.

PRENSKY, M. Digital native, digital immmigrants: part 1. On the Horizon, MCB University Press, v. 9, n. 5, 2001. Disponível em:

https://doi.org/10.1108/10748120110424816. Acesso em: 28 fev. 2020.

SILVA, Elizabeth M. O que dizem graduandos em pedagogia sobre suas práticas de leitura: o olhar dos letramentos acadêmicos. Leia Escola, Campina Grande, v. 19, n. 1, p. 200-211, 2019. Disponível em: 
http://revistas.ufcg.edu.br/ch/index.php/Leia/article/view/1292. Acesso em: 8 jun. 2019.

SILVA, Rickison Cristiano de Araújo; SOUZA, Fábio Marques de. O Teletandem como espaço para aprendizagem e formação de professores de línguas. Fólio - Revista de Letras, v. 11, n. 1, 2019. Disponível em: http://periodicos2.uesb.br/index.php/folio/article/view/5145. Acesso em: 28 fev. 2020.

SOARES, Magda. Letramento e alfabetização: as muitas facetas. Revista Brasileira de Educação, n. 25, p.5-17, 2004.

. Letramento: um tema em três gêneros. Belo Horizonte: Autêntica Editora, 2009.

STREET, Brian. (Org.). Introduction: the new literacy studies. In: Cross cultural approaches to literacy. Cambridge: Cambridge University Press, 1993.

. Os novos estudos sobre o letramento: histórico e perspectivas. In: MARINHO, M.; CARVALHO, G. (Ed.). Cultura escrita e letramento. Belo Horizonte: UFMG, 2010. p. 33-53.

. Eventos de letramento e práticas de letramento: teoria e prática nos novos estudos de letramento. In: MAGALHÃES, I. (Org.). Discursos e práticas de letramento: pesquisa etnográfica e formação de professores. Campina, SP: Mercado de Letras, 2012. p. 69-92.

. Políticas e práticas de letramento na Inglaterra: uma perspectiva de letramentos sociais como base para uma comparação com o Brasil. Cad. CEDES, Campinas, v. 33, n. 89, p. 51-71, 2013. Disponível em: http://dx.doi.org/10.1590/S0101-32622013000100004. Acesso em: 27 jun. 2019.

STREET, Brian; BAGNO, Marcos. Perspectivas interculturais sobre o letramento. Filologia e Linguística Portuguesa, n. 8, p. 465-488, 2006. Disponível em: DOI: https://doi.org/10.11606/issn.2176-9419.v0i8p465488. Acesso em: 04 jun. 2019.

TELLES, João A. (Org.). Teletandem: um contexto virtual, autônomo e colaborativo para aprendizagem de línguas estrangeiras no século XXI. Campinas: Pontes Editores, 2009. 
Práticas letradas digitais no contexto do teletandem...

TELLES, João A.; MAROTI, Fábio A. Teletandem: crenças e respostas dos alunos. In: PINHO, S. Z.; SAGLIETTI, J. R. O. C. Núcleos de ensino da UNESP: artigos dos projetos realizados em 2006. São Paulo: Cultura Acadêmica, 2008. p.1098-1124.

VASSALLO, Maria L.; TELLES, João A. Teletandem: uma proposta alternativa o ensino/aprendizagem assistidos por computadores. In: TELLES, J. A. (Org.). Teletandem: um contexto virtual, autônomo e colaborativo para aprendizagem de línguas estrangeiras no século XXI. Campinas: Pontes Editores, 2009. p. 41-61.

VÓVIO, Claudia L.; SOUZA, Ana. L. S. Desafios metodológicos em pesquisas sobre letramento. In: KLEIMAN, A. B.; MATENCIO, M. de L. (Orgs.). Letramento e formação do professor: práticas discursivas, representações e construção do saber. Campinas, SP: Mercado de Letras, 2005. p. 41-64. (Coleção Ideias sobre a Linguagem).

Recebido em: 25/08/2019

Aceito em: 25/02/2020

Title: Digital literate practices in the context of teletandem: a case study 